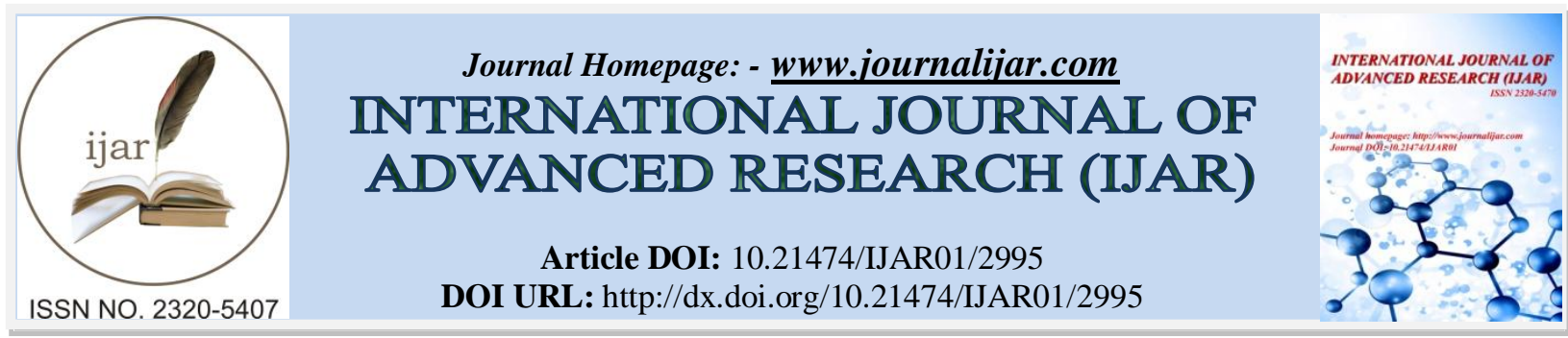

RESEARCH ARTICLE

\title{
INTRADURAL EXTRAMEDULLARY SPINAL CORD TUMORS: A RETROSPECTIVE STUDY OF LOCATIONS, TUMOR TYPES, AND SURGICAL OUTCOME
}

\author{
Dr. Sandeep Inchnalkar ${ }^{1}$, Dr. Kashif Ansari ${ }^{2}$, Dr. Suraj Mahadik² and Dr. Nikunj Shekhada ${ }^{2}$. \\ 1. Mch (neurosurgery). \\ 2. surgery post graduate.
}

\section{Manuscript Info}

(..........................

Manuscript History

Received: 28 November 2016

Final Accepted: 27 December 2016

Published: January 2017
Abstract

Introduction: Intradural extramedullary spinal cord tumors (IESCT) account for approximately two thirds of all intraspinal neoplasms. The purpose of this study was to determine short- and long-term outcomes of surgery in patients with IESCT, and to study the clinical features that could be helpful in treatment of patients with these lesions.

Methods: A retrospective review of 25 operative IESCT cases between 2012 and 2014 was performed. Outcomes were scored at one month and at mean follow-up of 9 months postoperatively. In addition, patient demographics, tumor subtypes and locations were also considered. Statistical analysis was calculated utilizing Chi-square and Student's t-tests.

Results: There were 8 men and 17 women (mean age 48 y/o, range $18-87 \mathrm{y} / \mathrm{o}$ ). Men presented at a younger age than women (44 vs 53 $\mathrm{y} / \mathrm{o}, \mathrm{P}<0.02) .18(72 \%)$ patients presented with severe radiculopathy and/or myelopathy. The remaining 7 (28\%) had symptoms typical of disc herniation. Mean duration of symptoms prior to diagnosis was 11 months. Schwannomas (10 patients) had the longest mean duration of symptoms (14.9 months), followed by meningiomas (8 patients, 8.4 months), and ependymomas (7 patients, 2 months).

Conclusions: Intradural extramedullary tumors, easily detected by MRI, are mostly benign and excellent clinicoradiological results can be obtained by microneurosurgery. Therefore, more active surgical approaches by neurosurgeons are recommended to decrease morbidity.

Copy Right, IJAR, 2016,. All rights reserved.

\section{Introduction:-}

Spinal tumors account for less than around $5-15 \%$ of the system neoplasms $(1,2)$. Intradural extramedullary spinal tumors (IESCT) represent around two thirds of those tumors $(2,3)$. Comparatively few printed reports have enough sample sizes to adequately analyze surgical outcomes, demographics, symptoms, and knowledge on growth varieties and locations $(3,4,5,6)$. The foremost unremarkably encountered kinds of IESCT are schwannomas and meningiomas, with myxopapillary ependymomas encountered less oftentimes. The first objective of this study was to look at surgical outcomes following procedures for IESCT in a large retrospective cohort of patients. Secondary goals enclosed examination of clinical knowledge relating demographics, symptoms, growth location and sort that might be useful in clinical deciding. 


\section{Materials and Methods:-}

This is a retrospective study of twenty five surgical patients underwent operative removal of IESCT between 2012 and 2014 at Dr. D. Y.PATIL HOSPIYTAL KOLHAPUR. Parameters recorded according to patients demographics, symptoms (severity and duration), growth characteristics (anatomic and pathologic), operative follow-up and surgical outcomes.

Surgical intervention was indicated by combination of presenting symptoms (radiculopathy and/or myelopathy) and photography findings of magnetic resonance imaging (MRI), and computed tomographic (CT)-myelography.

Surgical outcomes were scored at one month and so at the mean follow-up amount. The mean follow-up was calculated from the interval between surgery and therefore the last complete clinical examination within the patient chart (in this study, 9 months). Patient records were fastidiously reviewed and surgical outcomes were scored strictly in step with the changed criteria of Odom, et al (Table 1) (7).

While recognizing the shortcomings of the Odom's criteria as a 'rough' outcome and morbidity assessment scale, we have a tendency to selected to use this methodology attributable to the uniform and standardized recording of those criteria altogether of our patient charts.

Descriptive statistics, Chi-square check and Student's t-test were used for knowledge analysis. Applied math significance was set at alpha $=$ zero. 05 .

Figure 1

Table 1:- Modified Criteria of Odom, et al ().

$\begin{array}{ll}\text { Bxcellent } & \text { complete relief of pain and other symptoms", return to full activity } \\ \text { Good } & \text { partial relief of pain, complete relief of other symptoms", return to full activity } \\ \text { Foir } & \text { improvement with persistent limitation of activities } \\ \text { Poor } & \text { no improvement or further deterioration }\end{array}$

"note other symptoms = paresthesias, paresis, sensory loss

\section{Results:-}

There were seventeen ladies and eight men (mean age $48.7 \pm 16.56 \mathrm{y} / \mathrm{o}$, median $45.7 \mathrm{y} / \mathrm{o}$, varies $18-88 \mathrm{y} / \mathrm{o}$ ). Overall, men of younger age group presented than ladies (44.1 vs $53.5 \mathrm{y} / \mathrm{o}$, P\&lt; 0.02). The age distribution was bimodal with a serious peak around $40 \mathrm{y} / \mathrm{o}$ and a minor peak at around $70 \mathrm{y} / \mathrm{o}$.

There were 3 primary growth types: schwannomas (10/25), meningiomas (8/25), and myxopapillary ependymomas (7/25) (Table 2A). Schwannomas were comparatively more common in men, meningiomas comparatively more common in ladies, and ependymomas distributed equally (Table 2A). Patients with meningiomas attended be older (57.6 y/o) than those with schwannomas (44.0 y/o) and ependymomas (40.2 y/o, P\&lt; 0.01) (Table 2B). Growth locations varied between the 3 growths varieties in a very foreseeable fashion (Table 2C). Whereas schwannomas were distributed fairly equally among the 3 anatomic regions (cervical, thoracic, and lumbosacral), meningiomas predominated within the cervical and thoracic and ependymomas were predictably localized to the lumbar region. Of note, the magnitude relation of Schwannomas to Meningiomas to Ependymomas was around 5:4:2 during this study (actual magnitude relation 10:8:7).

The mean length of symptoms before designation was 11.3 months. Schwannomas had a statistically longer length of symptoms (14.9 months) than did meningiomas (8.4 months, P\&lt; 0.05) for cervical and body part tumors. Ependymomas had shorter length of symptoms (2.0 months) than schwannomas (10.8 months, P\&lt; 0.05) for lumbosacral tumors. 
Out of twenty five patients, $20(80.0 \%)$ had good results at one month, and twenty two (88\%) had good results at 9 months postoperatively (the mean follow-up, range 1.5 to thirty six months). At the one month follow-up, $32 \%$ $(8 / 25)$ patients had wonderful results, 56\% (14/25) had good results, $8 \%(2 / 25)$ had fair results, and $2.5 \%(1 / 25)$ had Poor result. The patient with a Poor result at one month follow-up had terribly severe presenting symptoms, had very little immediate post-surgical improvement, and however was upgraded to the good result upon future followup.

At mean follow-up of 9 months (range 1.5 to thirty six months), overall outcomes improved considerably. Fifteen patients $(60 \%)$ had wonderful results, thirty second $(8 / 25)$ had good results, and $8 \%(2 / 25)$ had fair results. Though at the 9 months mean follow-up the quantity of patients with poor results inflated by one, none of the patients had Poor results. The number of patients with wonderful results inflated by sixty fourth and therefore the number of patients with good results diminished by forty second (largely upgrades to wonderful). Just one patient with previously good result was downgraded to a fair result.

Three patients had multiple IESCT, all of that were schwannomas. One amongst these patients was NF-II positive. 3 patients developed repetition of their IESCT. 2 of those were schwannomas associate degreed one was an ependymoma.

While no metastases were noted throughout the 9 month mean follow-up amount (range one.5 to thirty six months), this study failed to specifically examine whether or not pathologic process illness did seem at a later time. No mortality was noted during this series, and therefore the solely complications enclosed a superficial wound infection and ending huskiness $n$ one patient.

\section{Figure 2}

Table 1:- Histological, demographic, and anatomic considerations for IESCT

A.Distrubution of tumor by histologic type and patient gender in the series

\begin{tabular}{|c|c|c|c|}
\hline Patient gender & Men & Ladies & Total \\
\hline Schwanoma & 3 & 7 & 10 \\
\hline Meningioma & 3 & 5 & 8 \\
\hline Ependymoma & 2 & 5 & 7 \\
\hline Total & 8 & 17 & 25 \\
\hline
\end{tabular}

B. Tumor incidence by age group

\begin{tabular}{|c|c|c|c|}
\hline Age & $<40$ & $40-80$ & $>80$ \\
\hline Schwanoma & 3 & 3 & 4 \\
\hline Meningioma & 1 & 4 & 3 \\
\hline Ependymoma & 3 & 2 & 2 \\
\hline Total & 7 & 9 & 9 \\
\hline
\end{tabular}

C. Tumor incidence by antomic location

\begin{tabular}{|c|c|c|c|}
\hline Location & Cervical & Thoracic & Lumbar \\
\hline Schwanoma & 3 & 3 & 4 \\
\hline Meningioma & 4 & 3 & 1 \\
\hline Ependymoma & 1 & 3 & 3 \\
\hline Total & 8 & 9 & 8 \\
\hline
\end{tabular}

\section{Discussion:-}

Surgery for IESCT is that the best treatment choice manufacturing wonderful overall results, with completes microsurgical excision being the modality of selection $(6,8)$. Trendy techniques change smart surgical outcomes with minmal morbidity and mortality (2, 3, 6, and 9). The present series corroborates this rivalry in this largely wonderful or smart results were achieved with few complications. In fact, no Poor results were noted during this study at the mean 9 month follow-up. Our findings believe those of others, with majority of clinical improvement noted either directly or at intervals 6 months of the operative intervention, with less notable clinical modification when this first amount (2). Alternative studies reported that length of surgical symptoms seems to correlate with operative improvement, which productive complete microsurgical neoplasm excision is of utmost importance (2, 
10,11). In terms of mortality, our result correlate well with alternative series, with a reported vary between $0-4.4 \%$ $(2,5,12$, and 13$)$.

Approximately $2 / 3$ of patients during this study intimate with residual focal deficits, none of that were disabling. Others report similar outcomes among patients with similarities to our patient sample, with important improvement in $62-88 \%$ of cases and clinical worsening in exactly a minority of patients $(1-5 \%)(2,3)$. Number of the patient outcomes and practical scores on discharge and/or follow-up might differ across studies because of different assessment tools being used by different authors $(2,3)$.

Reported frequencies of schwannomas among IESCT vary from forty third to sixty seven in alternative studies (53.7\% during this series) $(2,6,14,15)$. Schwannomas tend to supply localized pain, radiculopathy, and bodily structure equina syndrome. Most report schwannomas to be solitary, with a 2.5\% malignancy rate, which carries a poor prognosis (16). During this study, schwannomas were the sole cluster of tumors while not a predominant location of incidence, and grooved seventy fifth of perennial tumors.

In this series, patients with meningiomas were older than those with alternative neoplasm varieties. Findings during this series believe the literature in this meningiomas area unit the second commonest IESCT, with about $80 \%$ localized to the pectoral region (71\% during this series) $(6,10,16,17)$. Between $75 \%$ to $85 \%$ of patients with meningiomas area unit ladies ( $81 \%$ during this series), UN agency tend to be older than patients with schwannomas or ependymomas $(6,10,16)$. In line with previous reports, we have a tendency to found meningiomas to be additional aggressive in younger patients, with the higher incidence of myelopathy probably because of predilection of meningiomas for the thoracic region (18). Others describe higher operative morbidity related to IESCT set within the thoracic region (6). Meningiomas tend to supply the "dural tail" check in imaging scans in sagittal, axial, and coronal planes, and it's counseled that every one 3 planes of image be used (19). We have a tendency to follow this recommendation as a result of as several as 100 percent of meningiomas will be each intradural and meninges (20).

Myxopapillary ependymomas represent $14.9 \%$ on IESCT during this study, and though during this study ependymomas had equal distribution among men and ladies, another series reported doubly as several men as ladies (21). During this series, the mean age of the ependymoma cluster was below the mean age of patients with tumor or schwannoma. Symptomatically, ependymomas cared-for turn out bodily structure equina syndrome, localized pain, and radiculopathy.

A 4:2:1 quantitative relation of schwannomas to meningiomas to ependymomas was ascertained during this series. Though not specifically delineate by others, similar quantitative relation of neoplasm varieties will be noted in previous reports $(2,6,15)$.

\section{Conclusions:-}

Surgery for IESCT, with goal of complete neoplasm removal, may be a safe and effective choice. At the 9 month mean follow-up, majority of patients had complete or close to complete relief of symptoms and come back to full activity. In others, symptoms stopped progressing, and none of the twenty five patients worsened. Schwannomas and ependymomas were the sole histological varieties to recur. Demographic, tumor-specific and anatomic concerns are also clinically helpful once approaching IESCT.

\section{References:-}

1. Porchet F, Sajadi A, Villemure JG. Spinal tumors: clinical aspects, classification and surgical treatment. Schweiz Rundsch Med Prax. 2003;92:1897-1905.

2. Hufana V, Tan JSH, Tan KK. Microsurgical treatment for spinal tumors. Singapore med J. 2005;46:74-77.

3. Albanese V, Platania N. Spinal intradural extramedullary tumors. Personal experience. J Neurosurg Sci.

4. 2002;46:18-24.

5. Slin'ko EI, Al-Qashqish II. Intradural ventral and ventrolateral tumors of the spinal cord: surgical treatment and results. Neurosurg Focus. 2004;15:ECP2.

6. Peker S, Cerci A, Ozgen S, Isik N, Kalelioglu M, Pamir MN. Spinal meningiomas: evaluation of 41 patients. J Neurosurg Sci. 2005;49:7-11.

7. Prevedello DM, Koerbel A, Tatsui CE, Truite L, Grande CV, Ditzel LF, Araujo JC. Prognostic factors in the treatment of the intradural extramedullary tumors: a study of cases. Arq Neuropsiquiatr. 2003;61:241-247. 
8. Odom GL, Finney W, Woodhall B. Cervical disk lesions. JAMA. 1958;166:23-28.

9. Yasargil MG, DeLong WB, Guarnaschelli JJ: Complete microsurgical excision of cervical extramedullary and intramedullary vascular malformations. Surg Neurol. 1975;4:211-24.

10. Schaller B. Spinal meningioma: relationship between histological subtypes and surgical outcome? 2005;75:157-161.

11. Gelabert-Gonzalez M. Primary spinal cord tumors. An analysis of a series of 168 patients. Rev Neurol. 2007;44:269-274.

12. Sandalcioglu IE, Gasser T, Asgari S, Lazorisak A, Engelhorn T, Egelhof T, Stolke D, Wiedemayer H. Functional outcome after surgical treatment of intramedullary spinal cord tumors: experience with 78 patients. Spinal Cord. 2005;43:34-41.

13. Allen JC, Aviner S, Yates AJ, Boyett JM, Cherlow JM, Turski PA, et al. Treatment of high-grade spinal cord astrocytoma of children with "8 in 1" chemotherapy and radiotherapy: a pilot study of CCG-945. Children's Cancer Group. J Neurosurg. 1998;88:215-220.

14. Cohen AR, Wisoff JH, Allen JC, Epstein F. Malignant astrocytomas of the spinal cord. J Neurosurg. 1989;70:50-54.

15. el-Mahdy W, Kane PJ, Powell MP, Crockard HA: Spinal intradural tumors: Part I - Extramedullary. Br J Neurosurg. 1999;13:550-557.

16. Garrido P, Laher-Mooncey S, Murphree NL, Jonker N, Levy LF, and Makarawo S. Neoplasms involving the spinal cord in Zimbabweans: an analysis of 262 cases. Cent Afr J Med. 1994;40:201-204.

17. Fromme K, Miltner FO, Klawki P, Friedrich M. Spinal cord monitoring during intraspinal extramedullary tumor operations (peroneal nerve evoked responses). Neurosurg Rev. 1990;13:195-9.

18. Gelabert-Gonzalez M, Garcia-Allut A, Martinez-Rumbo R. Spinal meningiomas. Neurocirurgia (Astur). 2006;17:125-131.

19. Cohen-Gadol AA, Zikel OM, Koch CA, Scheithauer BW, Krauss WE. Spinal meningiomas in patients younger than 50 years of age: a 21-year experience. J Neurosurg. 2003;98:258-63.

20. Queckel LG, Versteege CW. The "dural tail sign" in MRI of spinal meningiomas. J Comput Assist Tomogr. 1995;19:890-2.

21. Souweidane MM, Benjamin V. Spinal cord meningiomas. Neurosurg Clin North Am. 1994;5:283-291.

22. Wippold FJ 2nd, Smirniotopoulos JG, Moran CJ, Suojanen JN, Vollmer DG. MR imaging of myxopapillary ependymoma: findings and value to determine extent of tumor and its relation to intraspinal structures. AJR Am J Roentgenol. 1995; 165:1263-7.

23. Brazier JE, Harper R, Jones NM, O'Cathain A, Thomas KJ, Usherwood T, Westlake L. Validating the SF-36 health survey questionnaire: new outcome measure for primary care. BMJ 1992;305:160-4.

24. Nurick S. The pathogenesis of the spinal cord disorder associated with cervical spondylosis. Brain 1972; 95:87100. 